\title{
Sustainability of Teachers' International Experiences: Conditions for Institutionalization of International Program Outcomes
}

\begin{abstract}
Anatoli Rapoport
Purdue University, 100 N. University Street, West Lafayette, IN 47907-2098, USA

Correspondence should be addressed to Anatoli Rapoport, rapoport@purdue.edu

Received 3 September 2010; Revised 28 February 2011; Accepted 1 April 2011

Academic Editor: Vincent Dupriez

Copyright () 2011 Anatoli Rapoport. This is an open access article distributed under the Creative Commons Attribution License, which permits unrestricted use, distribution, and reproduction in any medium, provided the original work is properly cited.

Since World War II international exchange and training programs for educators have increasingly played an important role in developing prospective consciousness and awareness of cultural diversity and global interdependence among teachers. However, international programs have always depended on extra educational factors such as political, ideological, cultural, or financial circumstances. As a result, program sustainability and proper institutionalization of program's results that are a testimony of achieved success, are both matters of concern for program developers and alumni. This paper identifies factors and contexts that facilitate sustainable development of international programs and institutionalization of their outcomes. Two cohorts of international teacher program alumni from Russia and the United States were interviewed about the impact of exchange programs on participants' status and pedagogies. The study demonstrated that respondents consider three factors, namely, motivational, administrative, and cooperative, most critical for the institutionalization of international program results.
\end{abstract}

\section{Introduction}

As a result of major cultural and political transformations in the world, international programs in education that initially started as a means for promoting Western values [1] have become an important component in developing global awareness and cross-cultural learning. Researchers of international exchange programs predicted that (a) international educational exchanges will increase, (b) the purposes of the agencies and individuals will be clarified, (c) procedures at all levels will be improved, (d) research into all aspects of crosscultural relations will be continued and expanded, and (d) the competence, professionalism, and understanding of the individuals involved in the operations of these programs will grow [2-5]. These predictions have been well justified. For 59 years (1949-2008), almost 29,000 foreign and more than 20,000 US educators participated in international exchange programs through Fulbright grants administered by the US Department of State [6]. More than 43,000 individuals participated in educational exchanges in 1964-2008 through Fulbright-Hays grants administered by the US Department of Education [6]. In different years, government-sponsored exchange and training programs accounted for 4 to 7 percent of all programs [7], besides the numerous international exchange programs for educators sponsored by private funds.

\section{International Programs and Teachers' Professional and Cultural Development}

The importance of international educational exchanges has been emphasized by many scholars and politicians. Educational exchange programs contribute greatly to the major goals of international understanding by promoting an awareness of the shared nature of most human concerns. They develop participants' understanding and respect for other people and their cultures, awareness of the increasing global interdependence between peoples and nations, ability to communicate with others, understanding of the necessity for international solidarity and cooperation, and awareness not only of the rights, but also the duties incumbent upon individuals, social groups, and nations towards each other [8]. Describing the significance of school exchanges, Burn [1] contended that "exchanges of teachers should have more priority and support because of their multiplier impact, 
assuming experience abroad affects what teachers teach and how, as well as their perceptions and attitudes towards other countries and cultures" (p. 131). Albert Shanker, president of the American Federation of Teachers, recommended that school teachers in all disciplines should be encouraged to attain proficiency in a foreign language and to teach abroad on exchange as part of this effort [1]. Teachers who have been short-term international sojourners teach more accurately, authoritatively, creatively, enthusiastically, with more understanding about places they have visited; they extend themselves to people of different cultural background and they are generally committed to passing on their knowledge to students and community [9].

Leestma [10], Associate Commissioner for International Education, summarized some of the values of the international exchange of teachers for American schools and the American people: (a) teachers have an opportunity to compare their own educational organizations with the systems of other countries, (b) teachers develop a better understanding of themselves and of their society through the perspectives gained by cross-cultural experience, (c) teachers acquire new educational and cultural knowledge, (d) teachers are more stimulating when they can draw on their first-hand experience, (e) with the exchange of teachers, the schools in both countries can move forward and enrich their regular instructional programs with this valuable opportunity for students and teachers to have a sustained experience with a citizen and a professional educator from another country, (f) exchange teachers, after returning from abroad, often share their new knowledge and experiences with civic groups and professional societies, thus influencing public understanding of international relations as well as classroom instruction, and ( $g$ ) the exchange teaching experience can grow into continuing and expanding bonds between the schools in both countries and in their respective communities.

Teachers' international experiences have become a powerful tool in reconceptualization of various curricular topics and in expanding pedagogical content knowledge. Teaching practices and curricular decisions made by exemplary teachers who reflect critically on their international experiences are usually characterized by cross-cultural experiential learning, emphasis on multiple perspectives and perspective consciousness, multiple realities, and multiple loyalties [11]. Classroom teachers involved in implementing international and global education in schools try (a) to make connections across cultures and civilizations and across global issues instead of teaching them separately, (b) to identify historical antecedents to current world issues and problems, (c) to link global content to the lives of their students, and (d) to teach tolerance and appreciation of cultural differences [12]. Many experienced teachers use reflection as their teaching strategy. Teacher's reflection is an integral step in developing instruction that brings about student reflection so that students can begin to see the world around them in new ways $[13,14]$.

Clearly, reflective strategies or experiential learning in international education assume direct contacts with other cultures and peoples. Direct interactions and contacts with different cultures, political or educational systems, and representatives of these cultures (a) improve teaching about the places visited, (b) engender educators' responsibilities for passing on the experience, for opening windows on the world to others, and (c) encourage teachers to try more cross-cultural encounters [9, 15]. Such contacts also help educators understand what it feels like to live outside of the mainstream. Merryfield [14] pointed out that the dissonance between identity and the meaning made of the experience during the encounter with another culture made "the lived experiences become, in retrospect, milestones in the development of a consciousness of multiple realities" ( $p$. 440). This recognition led many educators to realize that the multiple realities that exist in a community or country also exist globally $[14,16,17]$.

The immediate demands of today's world, the interdependence of the global economy, and the increasing ideological and cultural pressures experienced by contemporary students make international exchanges a meaningful tool in international and global education and an inseparable part of the educational process. Not only do they assist in an understanding of other cultures, they also make all agents of education aware of the multiple processes that take place in their own nations and communities. By the same token, experience in international and global education helps students develop personal qualities and skills, such as tolerance, perspective consciousness, acceptance of multiple realities, and global dynamics. In this situation, classroom teachers become key figures in providing the knowledge and skills necessary in international education. Exposure to various cultures, hands-on international experience, ability to critically compare the achievements of foreign and native cultures, experiential learning, and direct involvement in international programs, in their turn, become critical for truly international educators.

\section{Educational Changes and Patterns of Sustainability}

All international exchange programs, particularly training programs, are aimed at introducing and developing changes in various realms of education. Research shows that schools, by their nature, are very resistant to change and reform [18, 19], but in many cases, it is not the school bureaucracy that is to blame but the persistence and tenacity of what is routinely called the school culture and values that prevent new "foreign" trends from penetrating the educational process. Teachers and school administrators, in many cases, are too persistent in their values about students, their subjects, or methods of instruction [20-22]; they, as White [23] argued "shape incoming, new curricula, substituting them for what was formerly there, but transforming them so that they become just another means to serve the same overreaching cultural ends" (p. 239). On the other hand, there is evidence that if the knowledge, skills, and values newly obtained and observed in the course of international programs are thoughtfully interpreted and negotiated through the means of the existing educational and cultural discourses and then carefully placed in the framework and contexts of this 
culture, these new skills and knowledge become a meaningful and desirable tool in teachers' pedagogies [17, 24].

Implementing something new is difficult. Changing or implementing a new curriculum in a foreign classroom is even more challenging. The "natural" skepticism caused by teachers' values and the school culture is complicated by a disbelief in the ability of foreign methods to help, pride of success and the achievements of the participants' educational system, or suspicion of hidden self-interests [25-27]. Among the numerous factors that indicate the success of a program, sustainability, or its durability [28] plays one of the most important roles. The ability of an educational program to survive and endure over time is critically important for gradual change of the school climate and the evolutionary institutionalization of possible changes that this program is likely to trigger. However, researchers caution that not every adaptation actually becomes institutionalized [29]. One of the earlier institutionalization paradigms developed by Miles [30] demonstrated the sequence of actions that demystified the "mystery of institutionalization" (p. 14). The administrator, who worked from a centralized power base, put considerable pressure on teachers to implement the change. Despite the teachers' initial resentment and with the help of substantial assistance that increased the teachers' practice mastery, the stabilization of the change occurred. After teachers became committed to the change, the innovation was eventually institutionalized. Miles [30] demonstrated that such actions as administrative commitment, administrative pressure, administrative support, teachers' efforts, and teachers' commitments are indispensable elements in institutionalization. Krist and Meister [28], after examining school budgets and course enrollments, revealed the nature of long-term changes, which entailed three crucial attributes: "new structures, powerful constituencies, and easily accessible evidence of compliance" (p. 176).

More recent research has expanded the notion of sustainability. Studying why some technology-based innovations in schools fail while others succeed, Owston [29] identified two sets of conditions: those that are essential and those that contribute to sustainability. The essential requirements are teachers', principals', and students' support. Contributing requirements are support from others in the school and support from external sources. Hargreaves [31] argued that the concept of sustainability is much broader than simple endurance over time. This concept comprises five principal interrelated characteristics: (a) improvements that sustain learning, (b) improvements that endure over time, (c) improvements that can be supported by available or achievable resources, (d) improvements that do not impact negatively the surrounding schools and systems, and (e) improvements that promote ecological diversity in educational and community environments.

How sustainable are the outcomes of international programs in schools? Are the general conditions required for sustainability and institutionalization of programmatic changes also applicable to the outcomes of international exchanges? What are the curricular and instructional effects of a given program for a given teacher? It appears that after decades of exchange programs in education and thousands and thousands of alumni of those programs, we do not know much beyond descriptive articles or online success stories. In 1973, Leestma [10] wrote about the lack of understanding of the value of international teacher exchange. Eight years later, Hayden [32] complained that "very little is systematically known about the immediate let alone longerterm educational and personal impact of an international exchange experience" (p. 2). Quite recently, Craddock and Harf [33] contended that "without research and assessment, those who are involved in both the support and practice of promoting democratic education [through international programs] rely on anecdotal and intuitive analysis to inform their activities and planning" (p. 2).

\section{Context}

The majority of participants of this study were involved in exchange programs for educators sponsored by Western government and private funds in the late 1990's-early 2000s. The primary reasons for international exchange and training programs for educators since their mass inception after World War II were mostly the improvement of foreign language skills and area studies $[9,10,15]$. Dramatic changes in Europe in the late 1980s and the disintegration of the Soviet Union in 1991 gave a natural strong impulse to a whole series of projects and programs aimed at change of, or in some cases developing anew, the system of civic and economic education in the countries of the former Soviet Union, Central and Eastern Europe. Education in those countries faced multiple problems, such as excessive centralization and bureaucratization [34], unawareness of innovative methods of instruction, outdated textbooks and content materials $[35,36]$, and unwillingness and inability of many teachers to change [20] to name a few. Civic education, in whatever form it existed in the countries of the former Soviet block, experienced similar problems multiplied by the dependence of the former on sociopolitical situation. In this chaotic situation, the Western experience in the organization of civic and economic education was desired [37, 38].

Since 1995 with the help of Western government and private funds a number of projects on civic and economic education were started. Although every project was developed separately and was determined by specific features and conditions of a particular nation, the ultimate goals in all projects were defined by Quigley and Hoar [38]: "to acquaint educators from EEN/NIS with exemplary curricular and teacher training programs in civic education...; assist educators from EEN/NIS in adapting and implementing effective civic education programs in their own countries" ( $\mathrm{p}$. 13).

As it follows from the goals, an exchange and training component was a mandatory part of every project. The purposes of these exchanges were developing new curricula or new lessons, writing new textbooks or content materials, or observing and learning new methods and strategies.

Despite the amount of descriptive literature about international programs and projects in civics and economics, the evaluative literature is less numerous. The effectiveness of the conducted programs is usually measured either by 
numerical data (the number of seminars, workshops, or local educators involved in those seminars or workshops), or by the fact of publishing new curricula, textbooks, or teaching manuals. The outcomes of the programs measured through the changes in students' knowledge, participatory skills or dispositions $[33,35]$ are rare. This is also the case regarding the impact of those programs on the pedagogical practices of program participants. Understanding that it is not possible to judge the long-term effect of the international programs and projects, Quigley and Hoar [38] contend "clearly the civic education programs that have been developed in all of the participating countries have borne the hallmarks of the exchange experience" (p. 19).

In this paper, I will demonstrate and analyze the opinions of the alumni of international teacher exchange programs regarding the conditions that can help sustain the results of the international programs and eventually institutionalize them. For the purpose of this paper, I define sustainable outcome of an international program in education as a curricular activity or device that appeared in curriculum or in educational setting as the result of teacher's involvement in an international program and that at minimum meets the following conditions.

(i) It is used on a regular basis for longer than one year.

(ii) It gained support from administration whose commitment gradually turns into administrative pressure [30].

(iii) It became attractive to more than one individual in school and/or beyond [29].

(iv) It draws support and even commitment from external groups or entities [29].

\section{Method}

Data for this study were collected in 2005 and 2008 from two cohorts of alumni of several international exchange programs for educators from Russia and the United States. The first cohort of 26 Russian and 9 US educators was interviewed in 2005 in the course of a descriptive interpretive phenomenological case study whose purpose was to research the impact of international exchange and training programs on the curricular and pedagogical practices of their participants. The 2005 study participants were alumni of 4 different international exchange programs in civic education. They were selected through purposeful convenience sampling and were interviewed at six different locations in the United States and Russia. In 2008, the second cohort was interviewed. This cohort included 16 Russian and 4 US alumni of a 2007 exchange program sponsored by the US government. The 16 Russian teachers of the second cohort were English as Foreign Language (EFL) teachers, 4 US teachers taught Social Studies and Language Arts. The total number of participants interviewed for this study were 55. All 13 US participants were classroom teachers. Among 42 Russian participants only 16 worked as only classroom teachers and other 26 combined classroom teaching and administrative work, which is a normal practice for Russian schools. The US participants were from seven different states, while the Russian participants represented eight territories. All the participants in the study were working in education at the time of their international programs and had completed their exchange trips at least one year prior to the interview. The interviews with the US participants were transcribed verbatim, while the interviews with the Russian participants were translated and transcribed. The accuracy of translation was assured by back translation and member checking.

The data collected were then processed with the help of the inductive analysis method where the data are organized into categories, patterns, and themes, most of which emerge from the data, rather than being imposed on the data prior to their collection $[39,40]$. To insure data reliability, (a) only education professionals with experience in international programs were interviewed, (b) data collected in English from US participants underwent member checking, and (c) randomly selected Russian participants' interview transcripts were checked using back translation by two bilingual professionals who were not involved in the study.

On various stages of this study I encountered limitations that I had to consider. First, a convenience sampling procedure rather than random sampling was utilized due to a restricted access to databases of international programs for educators. Second, locations and conditions of data collecting determined the categories of educators that were interviewed. Many participants were interviewed during conferences that are traditionally attended by educators who can either afford it or who are to some extent independent in their actions. This explains a high percentage of administrators and officials among conference attendees. Third, interviews with Russian participants were conducted in Russian and then transcribed in English. Although two bilingual professionals conducted back translation to guarantee appropriate accuracy of translation, only several randomly selected interviews were checked with the help of back translation. Finally, researcher's own background and active involvement in international programs could make him unintentionally biased regarding the composition of interviews, construction of questions, remarks during interviews or observations, and also in the process of translation.

\section{Findings}

6.1. Personal Responsibility. Many participants felt personally responsible for preserving their programs and keeping the results sustainable. It is hard to say whether this feeling of responsibility was a result of the personal qualities of the participants, the sensation of the uniqueness of their experience, or, maybe, the understanding that others who "did not see it with their own eyes," as one of the participants put it, simply are not able to "carry the burden." As a result, the fear that the program or its outcomes would not last long if program alumni left their schools was expressed in many interviews. Henna (Cohort 1) was sure if she left her school, her experiences would leave with her, not because she was greedy and would take everything but because every 
teacher is unique and every teacher has his or her own style. Cleo (Cohort 1) also was pessimistic regarding the fate of the program and its outcomes. She knew this from her own experience. She had moved not long before the interview and she could observe how her initiatives had slowly died out in the school where she had worked before.

In general, the participants reported that they encountered ambivalent attitudes of their colleagues when they tried to implement their new knowledge and experiences in schools. They usually explained this apathetic and sometimes even unfriendly reaction either by the so-called "eyewitness effect," in which the alumni were convinced that they knew everything better than anybody else because they "saw it with their own eyes"; or by a simple jealousy, or as some participants called it "a worm inside," for those "lucky ones" who had participated in exchange programs. Irene (cohort 1) described such situations eloquently and emotionally:

Well, it was impossible to apply everything. Let us say, as to my round of responsibilities, I felt pretty free... in school we developed our own curricula, own strategies... I tried to use those. As for the activities that could be organized in several classes or school-wide, it was out of the question because teachers in our school, although they listened with interest to what I told them about the trip, but beyond that... I ran into a wall, there was no wish or intention from their side to do anything together, to try to accomplish together.

"Running into a wall" is a feeling that many informants experienced when they talked about the attitudes to which they wanted to bring into their schools. Respondents talked about "running into a wall" as well as positive experiences when they described their attempts to disseminate information through professional development workshops and seminars.

Some respondents were less pessimistic and more selfconfident. Helga (Cohort 1), for example, expressed her concern that when program alumni change their spheres of activity, this was a loss because "a lot of resources are deposited in programs and people." However, she was sure it was a natural loss. Such losses can be minimized by the "transmission of the received information and knowledge... through theory or practice, through seminars or dissemination of information, or with the help of development of new materials, or by new activities." Natalie (Cohort 2) noticed that even if a program alumna left the school, her colleagues already knew how to work. She never used the term 'teamwork" but her vision of keeping the program outcomes sustainable was very close to the "teamwork" category. Rupert (Cohort 1) understood the challenge of "program longevity": alumni want to immediately implement everything they learned in their programs, but this is hardly possible; it takes time. They have to convince their colleagues that what they bring is worthy. They have to find ways; they have to be diplomatic. They also have to think how they can change their behaviors. He decided he would give himself five years to implement the results of his program.
6.2. Creating a Team. Helga (Cohort 1) was not the only one who considered creating a group of people who were interested in promoting the results of exchange programs, which is a significant measure in keeping the program alive. Other participants, both US and Russian, told me how critically important it was in the implementation of the results of their programs to have a team of like-minded people. "The most important thing is to have a team, a team of like-minded people," said Claudia (Cohort 2) "Good God, I have such a team, so I can say that if I am gone one day the work won't stop." Angela (Cohort 1) suggested steps for creating a team of teachers and educators, "First, we have to raise people who will ensure sustainability. Second, to do some projects... Not just one seminar but... something on a regular basis." Delia (Cohort 1) hoped that if teachers got into teams, this would help support international programs. She hoped her experience would stay with her for a long time. She had presented her program in several schools, and her team helped to write a textbook and gave their feedback on what they had learned.

Tricia was active in organizing professional development seminars for her colleagues. She had planned her presentation even before the program:

I had enough time and opportunity... I began by presenting all materials, all pictures, all stories in schools. I presented in our school, 50 people who expressed great interest and listened to me with interest. I conduct seminars for teachers and with teachers' teachers, so I use everything I brought. We had planned a district conference before my trip. Then, approximately half a year later, I organized a two-day seminar in our school with the help of American Education Center. I invited Americans, with interactive methods, with the presentation of many various programs. Many of our teachers are still under impression of that seminar, and seminars that were a result of my trip.

Unlike teaching in one's own classroom where respondents were masters of the situation, dissemination of newly acquired information and pedagogical techniques through seminars or workshops was much more difficult. This is how Joshua described his "secret weapon" that he used to attract more colleagues to his presentations:

Were my colleagues dying to hear me to tell them my stories? In many cases-no. There were occasions when I might be invited into a class to tell about my experiences. But in general, it's difficult to get colleagues to be overwhelmingly interested in a program that you've been... in other word-professional development. If I say, "I am gonna have after school today a presentation on this experience in this program." Do I have a tremendous turn out for that type of thing? No. And are they really dying to see? No. How I've had to go about doing it? Food works wonders. I've had pizza, and brown bag talks 
in lunch time live, provided food and I've got pretty good turn outs with those things. Once they were there, and it's a very good situation, but if I had to say, "Come in this time," they would not be happy. They would feel as though there is another imposition on their already limited time.

Helen (Cohort 1), who worked as an instructor in one of the centers of extracurricular education, knew very well how teams of like-minded colleagues emerge. She explained that when teachers in Russia are invited to a professional development meeting, most of them do not come voluntarily, but only because their principals tell them to do so. If it is a regular seminar or workshop, only half of those who initially came to the first meeting will keep coming regularly. However, after the mandatory workshop is over, at least 15 or 20 percent of those who came to the first meeting will still want to meet again to discuss something that they became interested in during the workshop. Those 15-20 percent, Helen said, make up the core of the future team. She metaphorically called the creating of a team "seed planting".

6.3. Administrative Support. Many respondents specifically underscored how much the implementation of program outcomes and the sustainability of the programs depend on administrative support. Vladimir, Rosy, Lilia (all Cohort 1), Tatyana, Natalie, Irida, and Veronica (Cohort 2), all from Russia, simply said they could not imagine how they would be able to achieve everything they had planned without the support of their local Department of Education or regional Ministry of Education. Interestingly enough, Vladimir was a principal and Rosy was a high ranking regional education official. Polly (Cohort 1), who also worked as a principal, noted that school administrators can help change teachers' attitudes to new methods and approaches, "When we started projects in our town, we first invited principals and their deputies. Because if they don't support, teachers cannot do anything by themselves."

Fred (Cohort 1) and Tatyana (Cohort 2) argued that it was the administration, not the teachers who were more open to new ideas; therefore, it was easier to talk to principals and their deputies about the implementation of program results than to regular teachers. Teachers in schools are not well-prepared, Fred contended; they do not usually have an idea of what should be done to make a program work. School administrators have this conception; they are more motivated to implement changes.

In general, I did not hear much complaint about the school administration or local officials. If any criticism was expressed, it was indirect and mild. Henna (Cohort 1), for example, said that her colleagues and the school administration did not "stand in her way" because they did not want to look retrograde. Irene (Cohort 1), when asked about the attitude of her school administration to her program, simply reported that "the administration permitted [the trip] because it was during the school year and I had to get permission from the principal." Lora (Cohort 2) expected her supervisors to be less flexible; she was happy when they allowed her to participate in the program. Direct resistance from the school administration is very rare, contended Helga (Cohort 1); she personally had never heard of such cases. "But resistance is not necessary," she continued. "If a principal does not see much sense in a program, he can simply stop helping the teacher. And without help it is much more difficult for a teacher to do anything."

For the US respondents, the support for their participation in exchange programs and the following application of the new ideas in the classroom were practically self-evident. Why would they bother sending us and paying substitutes if they did not support the programs, asked Joshua (Cohort 1). He said his administration wanted to see the results of his program in return. Jacob's (Cohort 1) administration also was very supportive. Even his superintendent had been involved in this program even before Jacob was and, of course, supported it too. Rupert (Cohort 1) believed that his school administration supported his participation because they saw it as a "good thing":

Whether it is good or bad, the administration that I work with is very supportive of this. They, however, do not demand certain numbers of the presentations to be done, in-services done, neither that goes along with it. They look upon it as a good thing because it provides development that, I think, they see as being real because it includes some of the policy makers on various trips and such. So they understand what it's about and they endorse it as a good professional development, and we always try to demonstrate that students benefit, not just teachers but students.

\section{Discussion}

During the interviews, the participants did not seem or sound very much concerned about the sustainability of the outcomes of their programs. Almost nobody had an immediate answer; they either took a long pause or asked for time to think over a reply. Such an unexpected reaction, I admit, was disappointing at first. Was this a dangerous sign of indifference to a very important aspect of every exchange or training program? Only later, after I analyzed all interviews, did I realize that the ostensible reluctance to respond was most likely caused by the fact that a lot of what program participants could do had already been done. Most of my interviewees had been international program alumni for several years. By the time of the interviews, many of them had already accomplished a lot of what was related to their programs and the program outcomes had become part of their regular pedagogical or administrative routines. From this perspective, the perplexity caused by my question was a good and promising sign.

The data collected demonstrate that to be properly institutionalized and kept sustainable, international programs and their outcomes should meet three principal conditions: (a) a personal interest on the part of program 
alumni to actively implement the program outcomes in their pedagogies, (b) support of the school administration and local education authorities, and (c) a team of like-minded educators who are interested in promoting innovative teaching methods or new curricular materials. Many participants also underscored the importance of a combination of these measures together with publishing new textbooks, developing new curricula, or keeping regular contact with foreign partners.

7.1. Personal Interest of Alumni. No doubt, the alumni's personal interests and involvement in implementing program results are the single most important factor in promoting the outcomes of their programs and keeping them sustainable. Many participants told me how passionate they were in their wish to deliver information about their program and its results and also to secure speedy application of the newly acquired knowledge or skills in pedagogical practices. These personal interests and wishes are usually motivated by a number of factors, both external and internal. Among the external factors that motivated alumni were methodological and content literature or other artifacts that they were provided during their programs; regular contacts with the members of their groups and with the program coordinators, or genuine interest in the program or its results from the colleagues of the alumni.

However, it is internal motivation that plays the most important role in supporting international program alumni's interest in keeping the program outcomes sustainable. Among the internal motivational factors, two seem to be particularly important. They are (a) an eyewitness effect and (b) a pioneering effect. What I call an eyewitness effect is the program participants' conviction that they become an expert in an activity only because they saw this activity during the exchange program and now know that this activity brings about good results. A pioneering effect, in turn, is the participants' conviction that they are the first in their area, region, or country to start something new based on what they observed during the exchange program. Both of these phenomena are critically important in motivating teachers to actively pursue expedited implementation of the results of their programs. Nonetheless, the impact of these two effects can be controversial: I observed several cases where uncritical "blind" copycatting based on the eyewitness effect brought about the most undesirable results.

7.2. Seeking Administrative Support. Upon completion of the traveling component of an exchange program, alumni usually bring back a lot of new materials. Such novelties as new courses, new published materials, or even new curricula require administrative involvement and special permission to be implemented. Official support is also necessary for funding purposes. In the centralized and hierarchal system of Russian education, support from authorities is a carte blanche, which becomes even more important in a situation where everything connected with foreign contacts, particularly in such a sensitive area as education, can be highly politicized. I was appalled when one of the participants told me that her colleague had warned her, "Wait, we will see what you will say when ours come back!” As the participant explained, her colleague's husband worked in local government. Another participant risked her academic career by participating in an exchange program. Her doctoral dissertation defense was postponed because her academic advisor, as she recounted, considered her trip unpatriotic.

Suffice it to say, the majority of Russian participants reported good business relations with their school administrators or officials, and some of them were administrators or officials themselves. Before this study, I had often been unpleasantly surprised by the disproportionally large number of school administrators or officials among the participants in noncompetitive international programs that were supposed to consist primarily of classroom teachers. I was sure that this was the result of the access of the former to power. In the course of collecting data, I interviewed several international program developers and organizers, both Russian and US. It was not at all surprising that they were very well aware of this situation. Moreover, they did not see anything wrong with it (except, maybe, the really excessive number of officials in a few cases). They explained to me that inviting administrators and officials was sometimes even a better investment in the program than bringing classroom teachers because administrators and officials provided real support to the program. This study supports their views.

Interestingly enough, the perception of administrative support for sustaining and institutionalizing program results among Russian participants differs from that of US participants. Although both Russian and US alumni were convinced that administrative support was critical, the former insisted on seeking this support, whereas the latter were sure that such support was self-evident and guaranteed. Obviously, this difference was a result of the variability and dissimilarity of power relations in Russian and US school systems.

7.3. Creating a Team. The third measure that would help keep program outcomes sustainable is creating a team of like-minded individuals. All those who suggested this measure admitted that it was hardly possible to promote the ideas and practices that they acquired during their international programs alone without support from others. The process of creating a team is long and laborious. It requires patience, tolerance for the ideas of others, and understanding of the difficulties and circumstances in which other educators work. Nevertheless, the participants also realized the advantages that a team of practitioners who hold the same views can have. Creating a team of volunteers is also an outcome of international exchange programs in its own right because many participants observed this practice during their trips, met and talked with members of national and state educators' councils and centers, and studied the practices of public policy. In a country such as Russia, where civil society is only taking first steps and the phrase "trade union member" is almost profanity, creating a team of professionals who are united by one goal is a noble and bold endeavor, as well as a hopeful sign.

Teams usually grow out of seminars and workshops conducted by international program alumni. Initially, such 
seminars and workshops attract teachers who hope to hear "travelers' stories." Participants reported that normally three categories of listeners attend their seminars and workshops. First are teachers who personally know presenters; second are teachers who were mandated by their administrators to attend those meetings as a professional development event; third are teachers who volunteered to attend in the hope of learning something new. The representatives of this third category usually constitute the core of the future team. If seminars or workshops are conducted on a regular basis, say monthly, 15-20 percent of initial attendees can make up a team that begins to meet voluntarily outside the official seminar time.

As a result of the regular seminars and workshops, a team is created. Members of the team exchange materials and develop lessons and new curricular units. What is next? Ironically, this newly created team has to start searching for...administrative support. Administrative support will give the team an opportunity to use resources to buy books, to implement their lessons and units, and to rent offices for resource centers and educational centers. Eventually, they will need administrative support to institutionalize these teams, to make them heard, and to turn themselves into official or semiofficial bodies that can influence educational policies. Moreover, in the case of permanent educational reform, officials need creative teams as much as teams need the support of authorities. Summarizing the stories and judgments of the participants, it seems that the most plausible variant of institutionalizing the outcomes of international programs and keeping them sustainable is to make efforts in creating a team and finding administrative support simultaneously.

\section{Conclusion}

More and more educators from the United States and other countries are involved in educational exchanges. The international program alumni bring to their schools new knowledge, new experiences, and new visions of the world. These elements of the new gradually transform into new pedagogical practices and content materials that transcend curricula, facilitating both the students and the teachers to develop global awareness, multiple perspectives, interand cross-cultural competencies, as well as better understanding of their own culture. However, the observations demonstrate that the mere fact of teachers' participation in international programs does not guarantee widespread and unquestionable acceptance of the results of the program. The international exchange program does not end at the moment when the plane lands at the airport. On the contrary, the return of program participants to their schools marks a new step in the program development, namely, the implementation of program results and institutionalization of its outcomes.

Interviews with participants of international exchange programs from Russia and the USA identified among other conditions three mandatory conditions that if met, can help keep the programs and their results sustainable. These conditions are (a) personal interest of the program participant to implement and disseminate new knowledge and experience, (b) support of the administration in keeping the results of the program sustainable, and (c) creation of a group of like-minded colleagues motivated to institutionalize the new experiences. The first two conditions have already been described in the literature on the preservation and sustainability of educational changes $[29,30]$. The third condition, the creation of a group of like-minded colleagues seems to be a specific feature in the situation where the initiative to sustain and institutionalize changes does not come from above, as in the case of an officially mandated reform, but originates from teachers themselves, as in the case of curricular, programmatic, or methodological changes prompted by international exchanges.

A proper understanding of these conditions by teachers, administrators, international program developers, and coordinators will enhance the planning and conduct of international exchange programs. It will also make educators' new experiences more meaningful and useful in a practical way for themselves and for their schools.

\section{References}

[1] B. B. Burn, "New directions in international education," Annals of the American Academy of Political and Social Science, vol. 449, pp. 129-140, 1980.

[2] J. M. Davis, "Some trends in international educational exchange," Comparative Education Review, vol. 8, no. 1, pp. 48-57, 1964

[3] S. E. Deutsch, International Education and Exchange: A Sociological Analysis, The Press of Case Western Reserve University, Cleveland, Ohio, USA, 1970.

[4] M. J. Flack, "Results and effects of study abroad," Annals of the American Academy of Political and Social Science, vol. 424, pp. 107-117, 1976.

[5] W. F. Hull IV, W. F. Lemke Jr., and R. T. Houang, The American Undergraduate, Off-Campus and Overseas: A Study of the Educational Validity of Such Programs, University of California, Santa Barbara, Calif, USA, 1977.

[6] "J. William Fulbright foreign scholarship board (n.d.)," 44th Annual Report, U.S. Department of State, Washington, DC, USA, 2007-2008.

[7] U. S. Senate, "Exchange programs and the national interests," in Hearing Before The Subcommittee on Foreign Relations. 106th Congress, September 2000.

[8] W. B. Edgerton, "Who participates in education exchange?" Annals of the American Academy of Political and Social Science, vol. 424, pp. 6-15, 1976.

[9] A. H. Wilson, "Teachers as short-term international sojourners: opening windows on the world," The Social Studies, vol. 75, no. 4, pp. 153-157, 1984.

[10] R. Leestma, "International teacher exchange: value/summary of state regulations," U.S Office of Education program (ERIC Document Reproduction Service ED083157, 1973.

[11] M. M. Merryfield, "Pedagogy for global perspectives in educationeducation: studies for teachers' thinking and practice," Theory and Research in Social Education, vol. 26, no. 3, pp. 342-379, 1998.

[12] M. M. Merryfield, "In the global classroom: teacher decisionmaking and global perspectives in education," in Proceeding 
of the American Educational Research Association, ERIC Document Reproduction Service, New Orleans, La, USA, April 1994, D401249.

[13] M. M. Merryfield, "Reflective practice in global education: strategies for teacher education," Theory into Practice, vol. 32, no. 1, pp. 27-32, 1993.

[14] M. M. Merryfield, "Why aren't teachers being prepared to teach for diversity, equity, and global interconnectedness' A study of lived experiences in the making of multicultural and global educators," Teaching and Teacher Education, vol. 16, no. 4, pp. 429-443, 2000.

[15] A. H. Wilson, "Returned peace corps volunteers who teach social studies," The Social Studies, vol. 77, no. 3, pp. 100-106, 1986.

[16] C. Laskaridou and L. Cercu, "Experiential cultural learning activities: school trips and exchange projects," in Foreign Language Teachers and Intercultural Competence: An International Investigation, L. Cercu, Ed., pp. 110-119, Multilingual Matters Ltd, Tonawanda, NY, USA, 2005.

[17] A. Rapoport, "The impact of international programs on careers and pedagogical practices of their participants: Russian experience," Teachers and Teaching: Theory and Practice, vol. 14, no. 3, pp. 225-238, 2008.

[18] A. Gitlin and F. Margonis, "The political aspect of reform: teacher resistance and good sense," American Journal of Education, vol. 103, no. 4, pp. 377-405, 1995.

[19] D. Tyack and L. Cuban, Tinkering Toward Utopia: A Century of Public School Reform, Harvard University Press, Cambridge, Mass, USA, 1995.

[20] T. S. Popkewitz, B. R. Tabachnic, and G. Wehlage, The Myth of Educational Reform: A Study of School Responses to a Program of Change, The University of Wisconsin Press, Madison, Wis, USA, 1982.

[21] S. C. Richardson, "The principal: gatekeeper of change," Information analyses ED 297 472, 1987.

[22] G. Spindler, "Introduction," in Doing the Ethnography of Schooling: Educational Anthropology in Action, G. Spindler, Ed., Holt, Rinehart and Winston, New York, NY, USA, 1982.

[23] J. J. White, "What works for teachers: a review of ethnographic studies as they inform issues of social studies curriculum and instruction," in Review of Research in Social Studies Education, W. B. Stanley, Ed., pp. 1976-1983, ERIC Clearinghouse for Social Studies/Social Sciences Education, Boulder, Colo, USA, 1985.

[24] A. Rapoport, "International exchange programs for educators: the role of participants' culture in the interpretation of results," International Education, vol. 36, no. 2, pp. 83-105, 2007.

[25] D. Burton, "The myth of "expertness": cultural and pedagogical obstacles to restructuring East European curricula," British Journal of In-Service Education, vol. 23, no. 2, pp. 219-229, 1997.

[26] D. Burton and J. Robinson, "Cultural interference-clashes of ideology and pedagogy in internationalizing education," International Education, vol. 28, no. 2, pp. 5-30, 1999.

[27] E. Stones, "Donkeys and parrots," Journal of Education for Teaching, vol. 22, no. 1, pp. 5-8, 1996.

[28] M. W. Kirst and G. R. Meister, "Turbulence in American secondary school: what reforms last?" Curriculum Inquiry, vol. 15, no. 2, pp. 169-186, 1985.

[29] R. Owston, "Contextual factors that sustain innovative pedagogical practice using technology: an international study," Journal of Educational Change, vol. 8, no. 1, pp. 61-77, 2007.
[30] M. B. Miles, "Unraveling the mystery of institutionalization," Educational Leadership, vol. 41, no. 3, pp. 14-19, 1983.

[31] A. Hargreaves, "Sustainability of educational change: the role of social geographies," Journal of Educational Change, vol. 3, pp. 189-214, 2002.

[32] R. L. Hayden, "Issues in international education: exchange policy," in Proceeding of the National Council on Education Research, Washington, DC, USA, April 1981.

[33] A. W. Craddock and J. E. Harf, "Education for democracy in Ukraine: student learning through a US-UA Civic Education Project," in Proceeding of the Conference on Civic Education Research, Reno, Nev, USA, September 2004.

[34] M. Zahorska-Bugaj, "Poland after the democratic revolution: challenges for civic education," in Building Civic education for Democracy in Poland, R. C. Remy and J. Strzemieczny, Eds., pp. 41-54, National Council for the Social Studies, Washington, DC, USA, 1996.

[35] J. J. Patrick, T. S. Vontz, and K. K. Metcalf, "Learning democracy through project citizen in Lithuania, Latvia, and Indiana," The International Journal of Social Education, vol. 17, no. 2, pp. 49-68, 2002-2003.

[36] R. Remy and J. Stzemieczny, "Education for democratic citizenship in Poland," The International Journal of Social Education, vol. 12, no. 2, pp. 38-61, 1997.

[37] J. J. Patrick, "Civic education in former communist countries of central and Eastern Europe," Tech. Rep. 143, ERIC Document reproduction Service, Bloomington, Ind, USA, 1994, (ERIC Document reproduction Service No. ED374056).

[38] C. N. Quigley and J. N. Hoar, "Civitas: an international civic education exchange program," The International Journal of Social Education, vol. 12, no. 2, pp. 11-26, 1997.

[39] J. H. McMillan and S. Schumacher, Research in Education: A Conceptual Introduction, Longman, New York, NY, USA, 2001.

[40] M. Q. Patton, Qualitative Evaluation Methods, SAGE Publications, London, UK, 1980. 


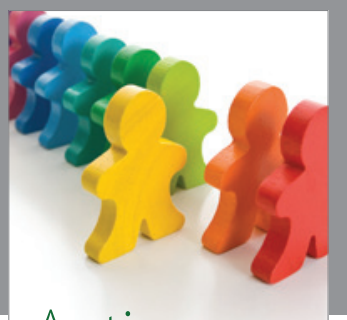

Autism

Research and Treatment
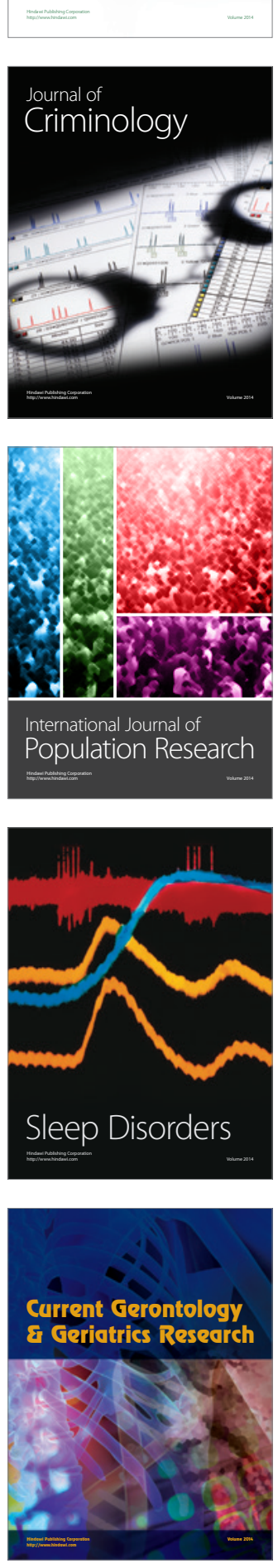
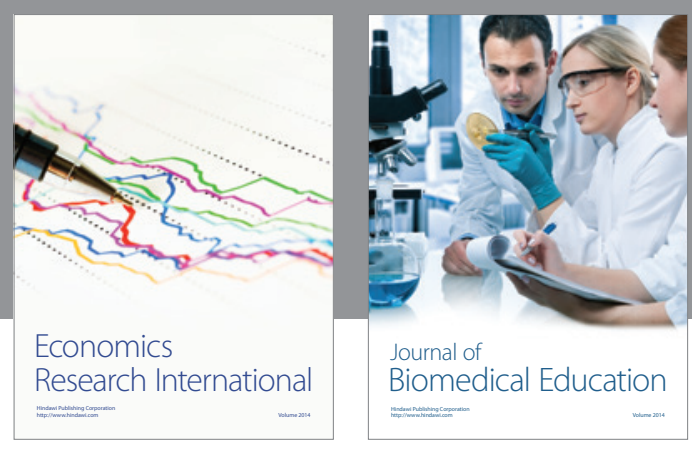

Journal of

Biomedical Education

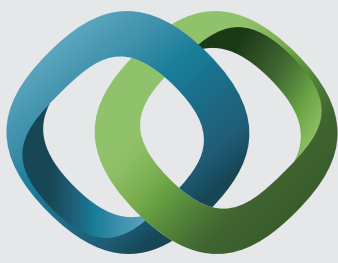

\section{Hindawi}

Submit your manuscripts at

http://www.hindawi.com
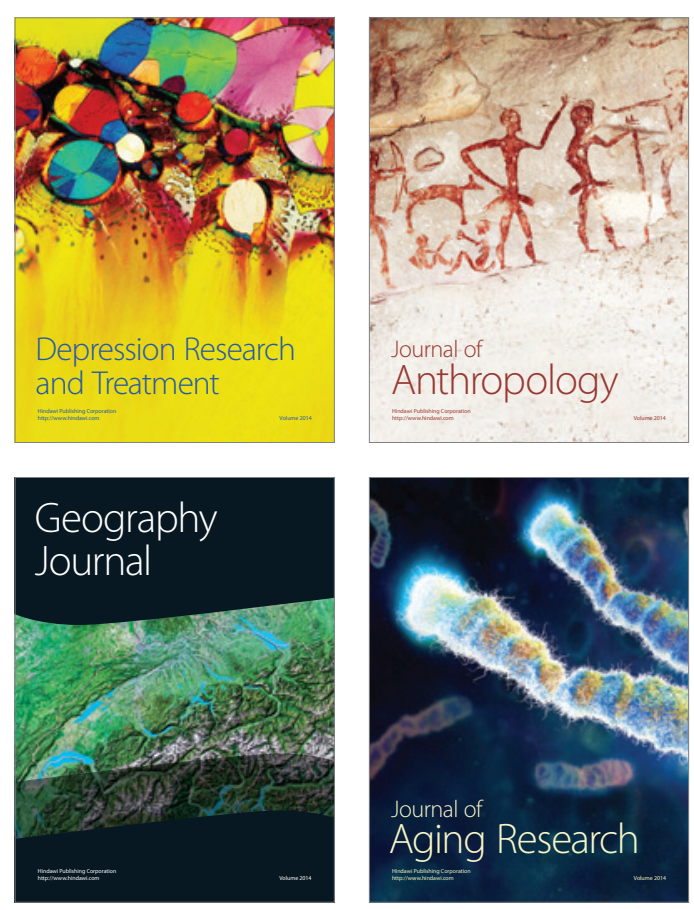

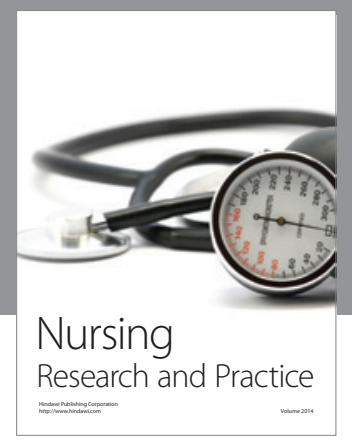

Nursing

Research and Practice

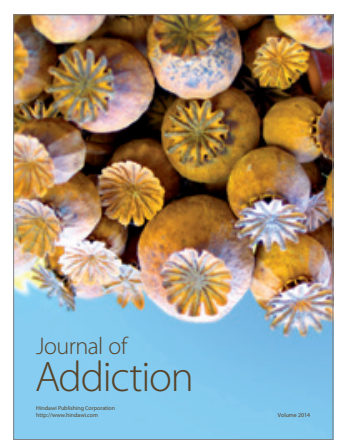

Child Development

Research

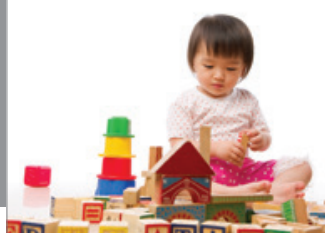

迥
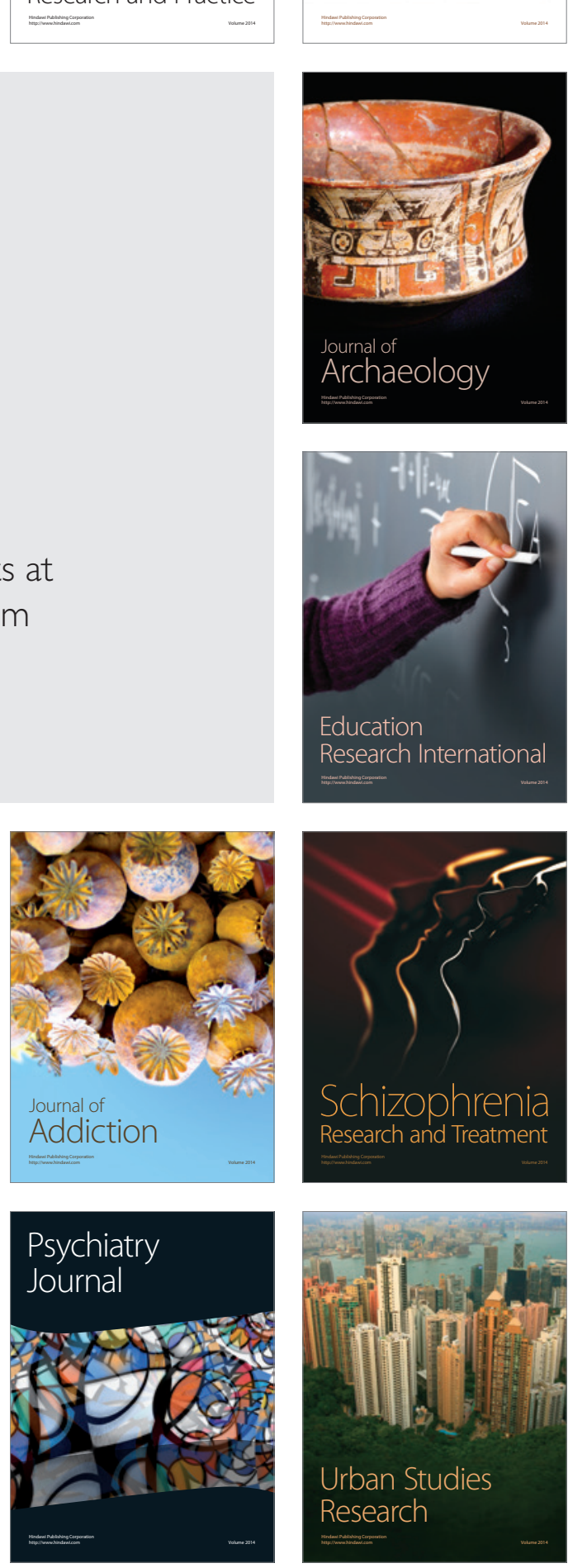